\title{
PROYECTO LECTURA Y ESCRITURA PARA NIÑOS
}

\section{Planteamiento del problema}

Dado el alto índice de repitencia en primero elemental (DANE, 1975) ${ }^{122}$ y las deficiencias de los diferentes métodos utilizados para la enseñanza de la lectura y la escritura aducidas por los maestros, como también la importancia de estas conductas como precurrentes para la adquisición de la mayoría de los contenidos académicos del actual currículo, se hizo necesaria la elaboración y experimentación de un método programado para la enseñanza de la lectura y la escritura.

A partir de 1974, año en el cual se hizo esta programación, se han llevado a cabo sucesivas investigaciones sobre diferentes variables relevantes tanto al material como al procedimiento de aplicación, teniendo en cuenta las ventajas cualitativas y cuantitativas (respuestas correctas y tiempo de aprendizaje) del método programado.

Considerando todas las modificaciones hechas era necesario poner a prueba todo el método, para verificar su efectividad comparándolo con el método más usado, hoy en día, en nuestras escuelas públicas, el de palabras normales.

\section{Objetivo}

Comparar la efectividad del método programado para la enseñanza de la lectura y la escritura con el método de palabras normales en términos de calidad del aprendizaje, es decir, respuestas correctas en las pruebas de adquisición, mantenimiento y generalización, y, tiempo empleado en el proceso de enseñanza-aprendizaje de estas conductas.

\section{Metodología}

Las etapas a seguir son las siguientes:

-Actualización de la bibliografía. Selección de la escuela, sitio de experimentación. Selección de la muestra: Aplicación de la prueba de lectura y escritura del programa para seleccionar los niños analfabetas.

-Aplicación de la prueba de conductas precurrentes a los niños analfabetas. Selección de los niños que tengan las conductas precurrentes. Apareamiento de los sujetos y formación de los dos grupos experimentales: Programado y Palabras Normales.

-Aplicación sucesiva de cada una de las 47 unidades que conforman el programa. Aplicación diaria de las pruebas de adquisición, mantenimiento y generalización a ambos grupos. Registro diario de las pruebas anteriores y elaboración de gráficas y cuadros. Análisis de resultados. Elaboración de informes parciales y anuales.

\footnotetext{
${ }^{122}$ DANE, Educación Primaria 1957-1974. Boletín Mensual de Estadística No. 288, julio de 1975. 
Adelantos de la investigación

Se escogió como sitio de experimentación la "Escuela Distrital Garcés Navas". Se seleccionaron 46 niños de 130 convocados y se formaron los dos grupos apareados: programado y tradicional, con 23 niños cada uno. A continuación se inició la aplicación de las vocales que constituyen las primeras 5 unidades del programa, con sus respectivas pruebas y registros de adquisición y mantenimiento de las conductas de lectura y escritura. 